\title{
Near Point of Convergence Deficits and Treatment Following Concussion: A Systematic Review
}

\author{
Ashley L. Santo, Melissa L. Race, and Elizabeth F. Teel
}

\begin{abstract}
Context: Convergence dysfunction following concussion is common. Near point of convergence (NPC) is a quick and easy assessment that may detect oculomotor dysfunction such as convergence insufficiency (CI), but NPC measurements are rarely reported. Convergence dysfunction is treatable in otherwise healthy patients; the effectiveness of oculomotor therapy following concussion is unclear. Objectives: The purpose of this article was to systematically review the literature and answer the following clinical questions: (1) Is performance on NPC negatively affected in patients diagnosed with a concussion compared with preinjury levels or healthy controls? (2) In patients diagnosed with concussion, what is the effect of oculomotor/vision therapy on NPC break measurements? Evidence Acquisition: The search was conducted in CINAHL, SPORTDiscus, MEDLINE, and PubMed using terms related to concussion, mild traumatic brain injury, convergence, vision, and rehabilitation. Literature considered for review included original research publications that collected measures of NPC break in concussion patients, with a pretest-posttest comparison or comparison with a healthy control group. A literature review was completed; 242 relevant articles were reviewed, with 18 articles meeting criteria for inclusion in the review. Evidence Synthesis: Articles were categorized according to the clinical question they addressed. The patient or participant sample (number, sex, age, and health status), study design, instrumentation, or intervention used, and main results were extracted from each article. Conclusions: The authors' main findings suggest that there is a moderate level of evidence that patients have impaired NPC up to several months postconcussion, and a low level of evidence that impairments can be successfully treated with oculomotor therapy. These findings should be cautiously evaluated; the studies are limited by weak/moderate quality, small sample sizes, varied methodology, and nonrandomized treatment groups. Future research should explore factors affecting convergence postconcussion and include randomized, controlled studies to determine if performing vision therapy improves visual measures and promotes recovery.
\end{abstract}

Keywords: neuroscience, recovery, rehabilitation, brain-concussion, evaluation

Traumatic brain injury (TBI) is a public health concern. TBI is common in sports and can be difficult to diagnose. Concussion, a form of mild traumatic brain injury (mTBI), can be defined as "a complex pathophysiological process" 1 in which damage occurs to the brain, causing a wide variety of signs and symptoms, including cognitive and physical impairments. Generally, these impairments resolve over several weeks, as the brain recovers. Some individuals experience lasting impairments, potentially for several years following concussion. ${ }^{2}$ Unfortunately, there is no gold standard for the assessment of concussion. Currently, the recommendation is to use a multitude of assessments, including a clinical examination, symptoms, neurocognitive, and balance assessments. ${ }^{3}$ Several researchers and clinicians have suggested that instead of categorizing concussion as a single diagnosis, health care professionals may be able to identify specific clinical trajectories or subtypes of concussion. ${ }^{4-6}$ Proposed subtypes of concussion include cervical, cardiovascular, cognitive/fatigue, mood/affective, headache/ migraine, vestibular, and visual/oculomotor. ${ }^{4-6}$ In order to identify these various trajectories, a comprehensive evaluation including assessments in several clinical domains must be used. Therefore, it has been suggested that clinicians should use vision or oculomotor assessments to aid in the diagnosis and treatment of concussion. ${ }^{7}$

Santo and Race are with the Department of Kinesiology, Towson University, Towson, MD. Teel is with the School of Physical and Occupational Therapy, McGill University, Montreal, QC, Canada. Santo (asanto@towson.edu) is corresponding author.
It is likely that the visual system is affected following a brain injury, because over half of the brain's circuits are involved in vision. ${ }^{8}$ Subjective visual complaints, such as blurred vision, light sensitivity, and difficulty reading, ${ }^{9-11}$ and objective oculomotor impairments are common following concussion. ${ }^{12}$ Several vision assessments have been proposed for inclusion in the evaluation of concussion, ranging from simple inexpensive clinical measures to assessments that are expensive and use sophisticated equipment. ${ }^{13}$ These assessments measure various aspects of vision, such as saccades, smooth pursuits, accommodation, and convergence. ${ }^{13}$ One vision assessment that is showing promise is convergence, which is commonly evaluated by measuring near point of convergence (NPC).

In recent years, convergence insufficiency (CI) has been identified in patients following concussion. $\mathrm{CI}$ is a binocular vision disorder, often characterized by exophoria and reduced positive fusional vergence at near, and receded NPC.${ }^{14}$ NPC is clinically useful, because it is used as one of primary diagnostic tests in the assessment of CI. ${ }^{15}$ While NPC is typically used as part of the criteria for diagnosis of CI, receded NPC and CI are not synonymous. There is some variability in the criteria used for CI, such as measurement parameters of abnormal NPC (eg, $>5 \mathrm{~cm}^{7,14,16,17}$ vs $17.5 \mathrm{~cm}^{18}$ ). Rates of CI in the healthy population are about $5 \% .{ }^{14} \mathrm{CI}$ following concussion has been recognized throughout various forms of sports medicine and ocular scientific literature. Values for the rate of $\mathrm{CI}$ following concussion range from $42 \%{ }^{16}$ to $55 \% .^{19}$ While many patients with receded NPC have CI, not all patients with receded NPC meet the criteria to be diagnosed with CI. ${ }^{20}$ In a 
recent study, $89 \%$ of symptomatic postconcussion patients had receded NPC, while only $36 \%$ met the criteria for CI. ${ }^{20}$ However, among patients with receded NPC, 95\% had an oculomotor disorder. ${ }^{20}$ The majority of studies that examine convergence dysfunction following concussion focus on a diagnosis of CI, and fail to report whether or not patients had receded NPC. Diagnosis of CI requires the use of more sophisticated measures, whereas NPC is a simple clinical measure that can be used by a variety of clinicians. While several methods of measuring NPC exist, typically a target (vertical line, pencil tip, fingertip, etc) is moved slowly toward the patient's nose, until it appears double or the examiner notices an eye deviating outward (exophoria). The distance measured from the target to the patient's nose when it appears double or exophoria is noticed and recorded as the NPC break. NPC recovery is the point measured from the tip of the nose to the target when the target appears single again, as the target is moved away from his/her nose. Receded NPC break is likely to be associated with various underlying oculomotor dysfunctions, so it may be a quick and easy way to identify patients in need of referral for oculomotor dysfunction following concussion.

Identifying domains of impairment following concussion can lead to establishment of targeted active interventions. Interventions such as oculomotor therapy with a focus on vergence could promote recovery in concussed individuals. Patients with visual deficits that go unidentified or unaddressed could have a prolonged recovery. In fact, after controlling for confounding variables, concussion patients with $\mathrm{CI}$ had an increased risk of prolonged recovery ( $\geq 28 \mathrm{~d}$ from injury) by 12.3 -fold. ${ }^{21}$ Patients with visual dysfunction following concussion also have higher symptoms scores, reduced reading abilities ${ }^{22}$ and impairments on verbal memory, visual motor speed, and reaction time. ${ }^{16}$ Additionally, binocular vision is one of the most important visual cues for spatial orientation, making it of utmost importance in many sports. Athletes perform significantly better than nonathletes on measures of vergence facility, saccades, visual reaction time, peripheral awareness, and NPC. ${ }^{23}$ Therefore, visual dysfunction in athletes may not only affect quality of life, but ability to return to sport as well. It is important to identify if impairments in NPC exist following concussion so that patients with receded NPC can be referred to an eye care specialist for further evaluation and possibly treatment. Several studies have demonstrated that CI is treatable in an otherwise healthy population through vision therapy. ${ }^{24-26}$ These findings cannot be directly applied to a concussed population, because CI following concussion appears to be due to a different mechanism. ${ }^{27}$ Therefore, it is important to determine if oculomotor or vision therapy is effective in improving convergence in patients with receded NPC following concussion. We conducted a systematic review of the literature to synthesize the current evidence around this topic and provide clinical recommendations when appropriate.

\section{Objectives}

This literature review discusses the effects of concussion on NPC and the efficacy of oculomotor and vision therapy in the treatment of CI following concussion. The purpose of this article was to systematically review the literature and answer the following clinical questions:

1. Is performance on NPC break negatively affected in patients diagnosed with a concussion compared to pre-injury levels or healthy control participants?

2. In patients diagnosed with concussion, what is the effect of oculomotor or vision therapy on NPC break measurements?

\section{Evidence Acquisition}

An electronic search was conducted in 4 databases (CINAHL, SPORTDiscus, MEDLINE, and PubMed). A summary of the search terms used, and number of articles resulting from the search are included in Table 1. We also performed hand searches for relevant citations on all included articles. All searches were conducted between February 15, 2019 and April 1, 2019. Therefore, only articles published from database inception to April 1, 2019 were included in this review.

At the conclusion of the search, duplicates were removed. Two reviewers (A.L.S. and M.L.R.) screened titles and abstracts of all primary articles to determine studies eligible for inclusion. If there was not sufficient information in the title and abstract to determine whether or not inclusion criteria were met, a full-text evaluation was performed. The same 2 reviewers then independently evaluated the full text of potentially relevant articles. If there were conflicts or disagreements about whether or not an article should be included, a meeting was held to obtain a consensus. The following inclusion criteria were used:

1. Published prior to April 1, 2019

2. Published in English

Table 1 Search Terms and Number of Articles Identified by Database

\begin{tabular}{|c|c|c|c|c|c|}
\hline Search terms & CINAHL & SPORTDiscus & MEDLINE & PubMed & Total \\
\hline Concussion AND convergence & 45 & 22 & 65 & 65 & 197 \\
\hline $\begin{array}{l}\text { Concussion AND convergence AND rehabilitation or therapy } \\
\text { or treatment }\end{array}$ & 13 & 9 & 28 & 29 & 79 \\
\hline Concussion AND vision AND rehabilitation or therapy or treatment & 42 & 24 & 88 & 97 & 251 \\
\hline Concuss* AND convergence & 46 & 22 & 66 & 67 & 201 \\
\hline Concuss* AND convergence AND rehabilitation or therapy or treatment & 15 & 9 & 28 & 29 & 81 \\
\hline Concuss* AND vision AND rehabilitation or therapy or treatment & 45 & 24 & 92 & 99 & 260 \\
\hline Mild traumatic brain injury AND convergence & 46 & 6 & 70 & 40 & 162 \\
\hline $\begin{array}{l}\text { Mild traumatic brain injury AND convergence AND rehabilitation } \\
\text { or therapy or treatment }\end{array}$ & 13 & 6 & 27 & 17 & 63 \\
\hline $\begin{array}{l}\text { Mild traumatic brain injury AND vision AND rehabilitation or therapy } \\
\text { or treatment }\end{array}$ & 52 & 18 & 85 & 73 & 228 \\
\hline Total & 317 & 140 & 549 & 516 & 1522 \\
\hline
\end{tabular}


3. Participants must have been human (ie, no animal studies)

4. Original research

5. Must have included participants diagnosed with a concussion or mTBI

6. Must have included a measure of NPC break, with either a pretest-posttest comparison, or a comparison to a healthy control group.

Data were independently extracted by 2 reviewers to carry out descriptive analyses. Articles were categorized according to the clinical question they addressed. The patient or participant sample (number, sex, age, and health status), study design, instrumentation, or intervention used, and main results were extracted from each article. Means and SDs for NPC break measurements were obtained if available. Meta-analyses were not performed, because studies were heterogeneous in sample (participant age and general characteristics) and methodology. In accordance with previous literature, ${ }^{7,14,16,17}$ NPC measurements $>5 \mathrm{~cm}$ were considered abnormal for the purpose of this review. Many of the studies had primary and secondary outcomes. We limited extraction and presentation of the outcomes to those that fit the clinical questions of interest for this review. The quality of the articles was assessed, and studies were assigned a level of quality as described by the quality assessment tool for quantitative studies (QATQS). ${ }^{28}$ The QATQS has been demonstrated to have fair to excellent interrater reliability ${ }^{28}$ and acceptable construct validity. ${ }^{29}$ The tool evaluates 8 components, including selection bias, study design, confounders, blinding, data collection methods, withdrawals and dropouts, intervention integrity, and analyses. Each component is rated as weak, moderate, or strong. An overall or global rating is assigned to the paper as follows: weak ( 2 or more weak ratings on first 6 components), moderate (one weak rating on first 6 components), or strong (no weak ratings on first 6 components). Scores were agreed upon by 2 reviewers consistent with the instructions for the QATQS. ${ }^{28}$ Finally, we graded our recommendations using Grading of Recommendations, Assessment, Development and Evaluations (GRADE). ${ }^{30}$ The GRADE is a framework for summarizing evidence and providing clinical recommendations. ${ }^{30}$ An overall GRADE rating was applied to the outcome for each of our clinical questions. GRADE has 4 levels of evidence, including very low, low, moderate, and high. ${ }^{30}$ Levels of evidence were agreed upon by 2 reviewers.

\section{Evidence Synthesis}

A total of 1522 studies were initially identified through the electronic database searches (Table 1). After exclusion of duplicate articles $(\mathrm{n}=1281), 241$ articles were screened. Of the remaining articles, 191 articles were removed due to title/abstracts alone and 33 studies were removed after full-text evaluation. Articles were removed if they did not meet the inclusion criteria for the study (Figure 1). A total of 18 studies met the inclusion criteria for this review; 11 articles assessed the effects of concussion/mTBI on NPC break and 7 articles addressed the effect of oculomotor or vision therapy on NPC break measurements in concussion/mTBI patients.

Eleven studies evaluated the effects of concussion on NPC break measurements (Table 2). All of the studies were prospective and included the following designs: case-control, ${ }^{9,32}$ cohort, ${ }^{34,37}$ controlled observational, ${ }^{35}$ cross sectional, ${ }^{7,36,38}$ and repeated measures. ${ }^{17,31,33}$ While Capó-Aponte et al ${ }^{31}$ used a repeated-measures

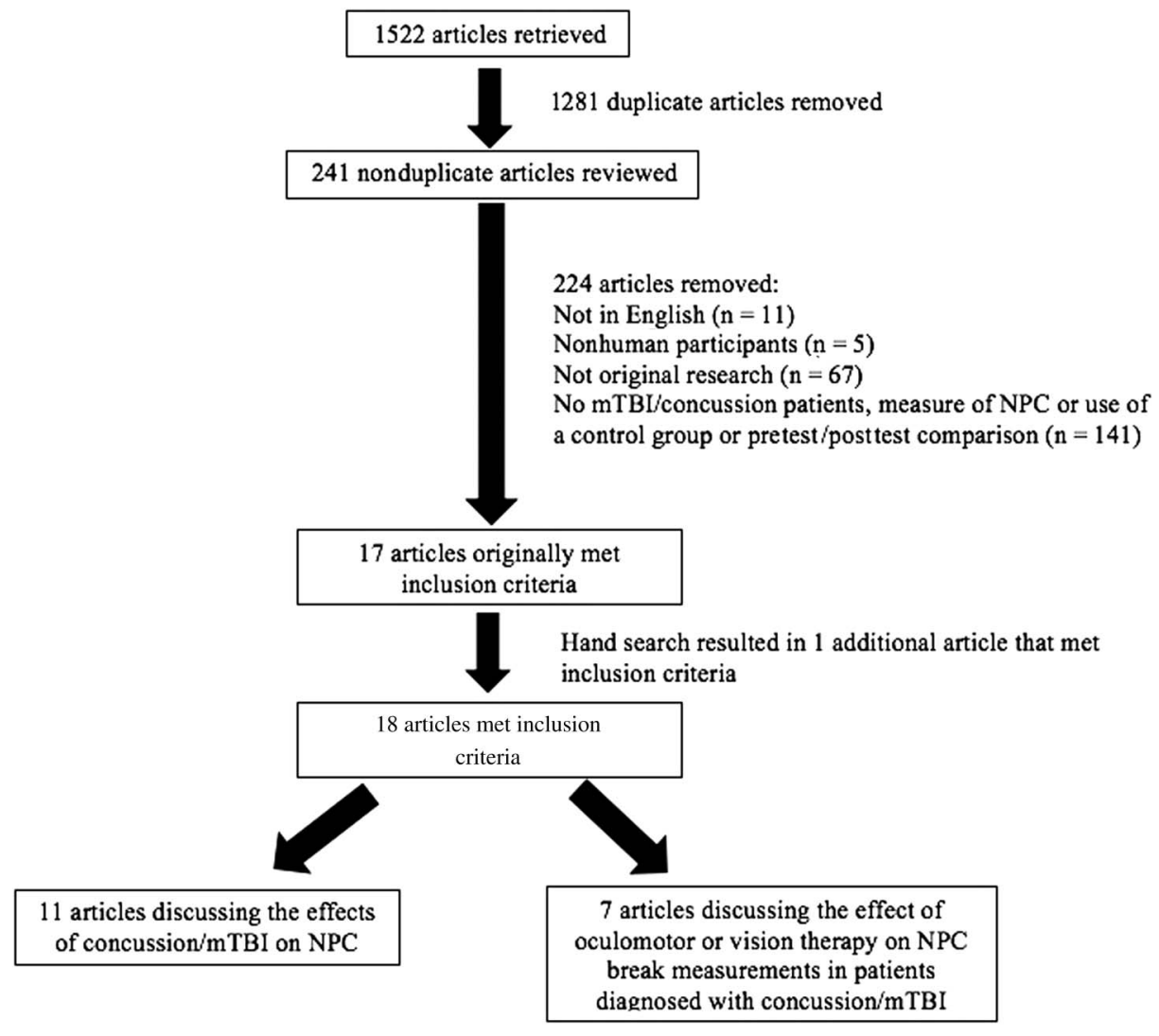

Figure 1 - Study selection process. mTBI indicates mild traumatic brain injury; NPC, near point of convergence. 

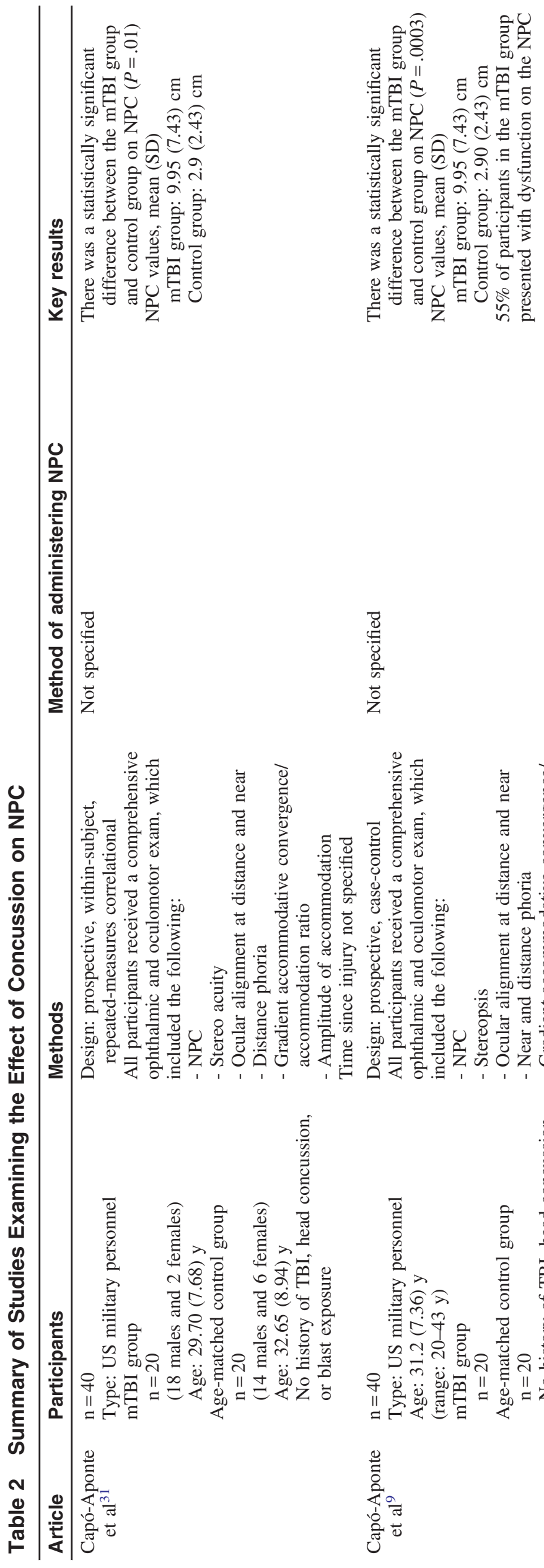

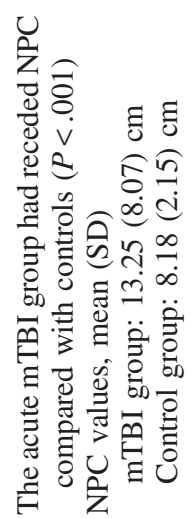

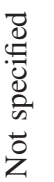
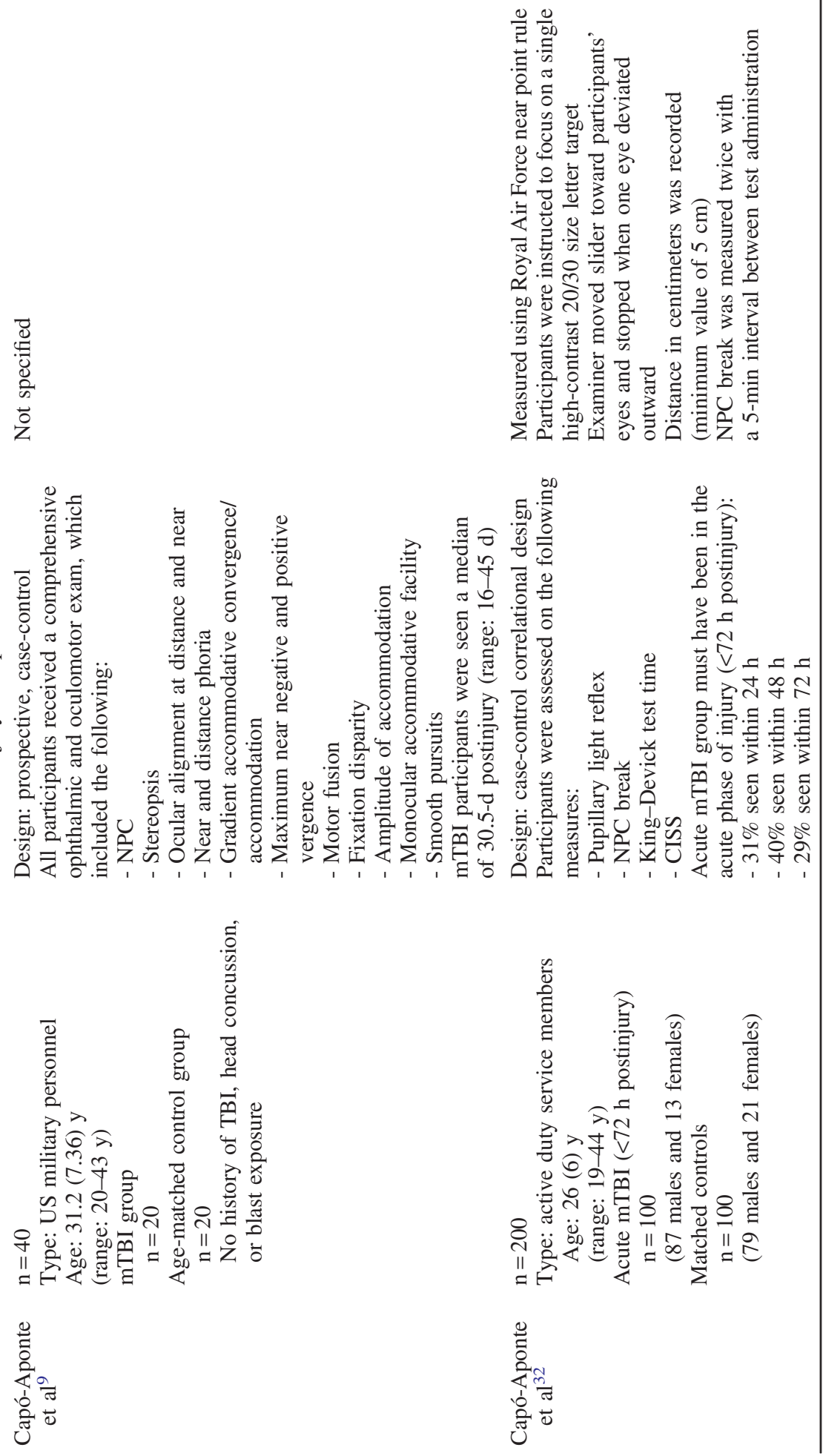


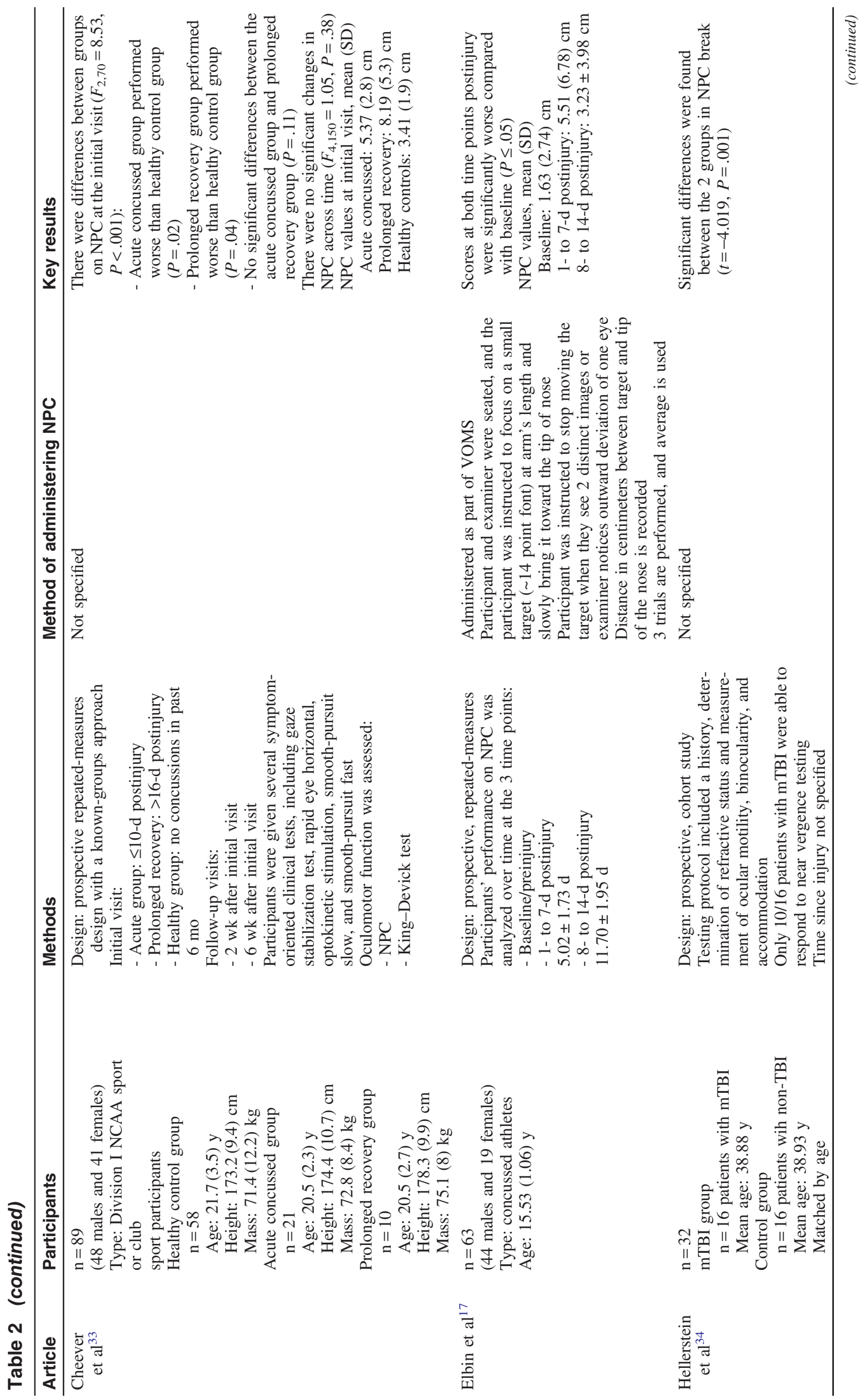




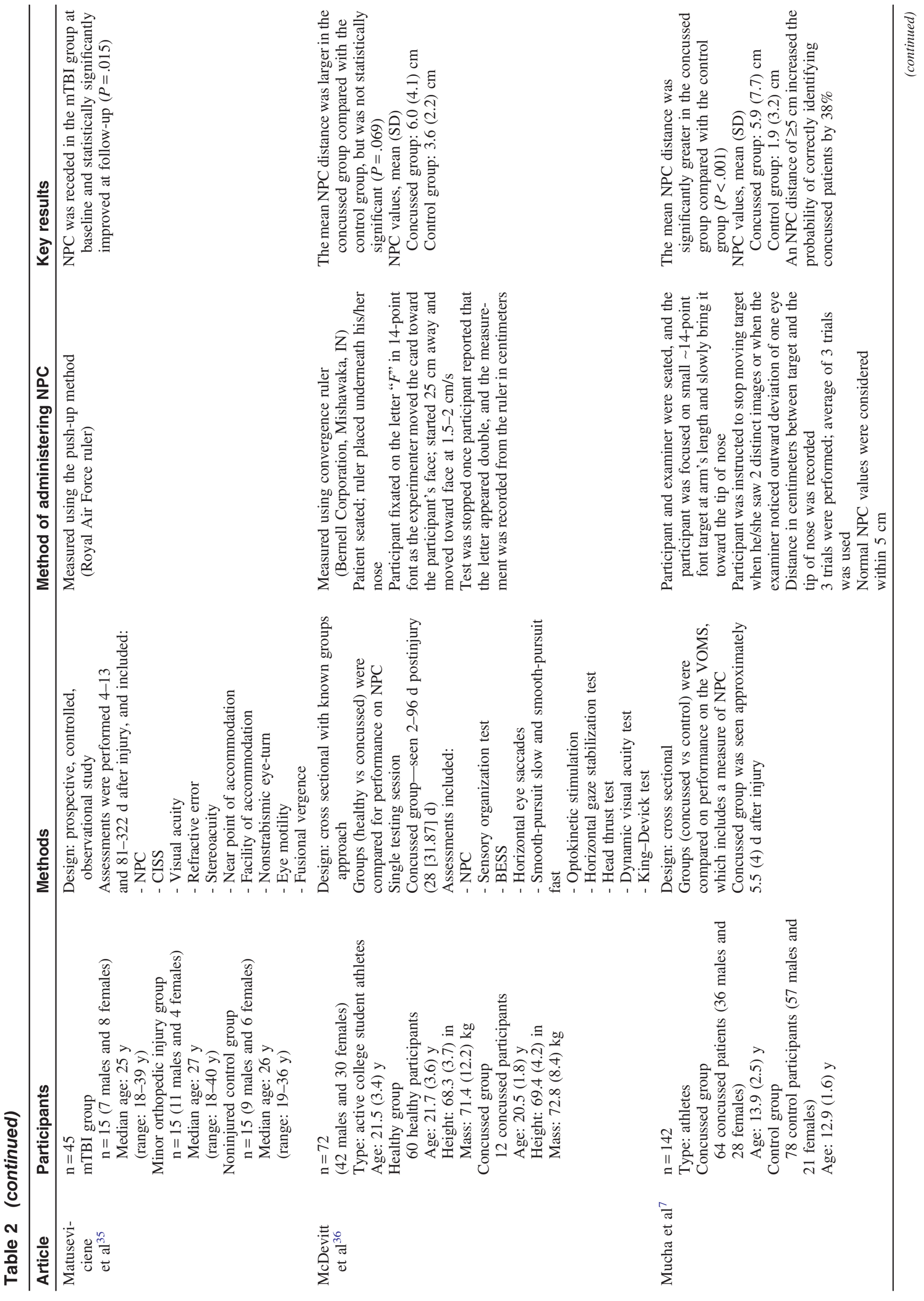




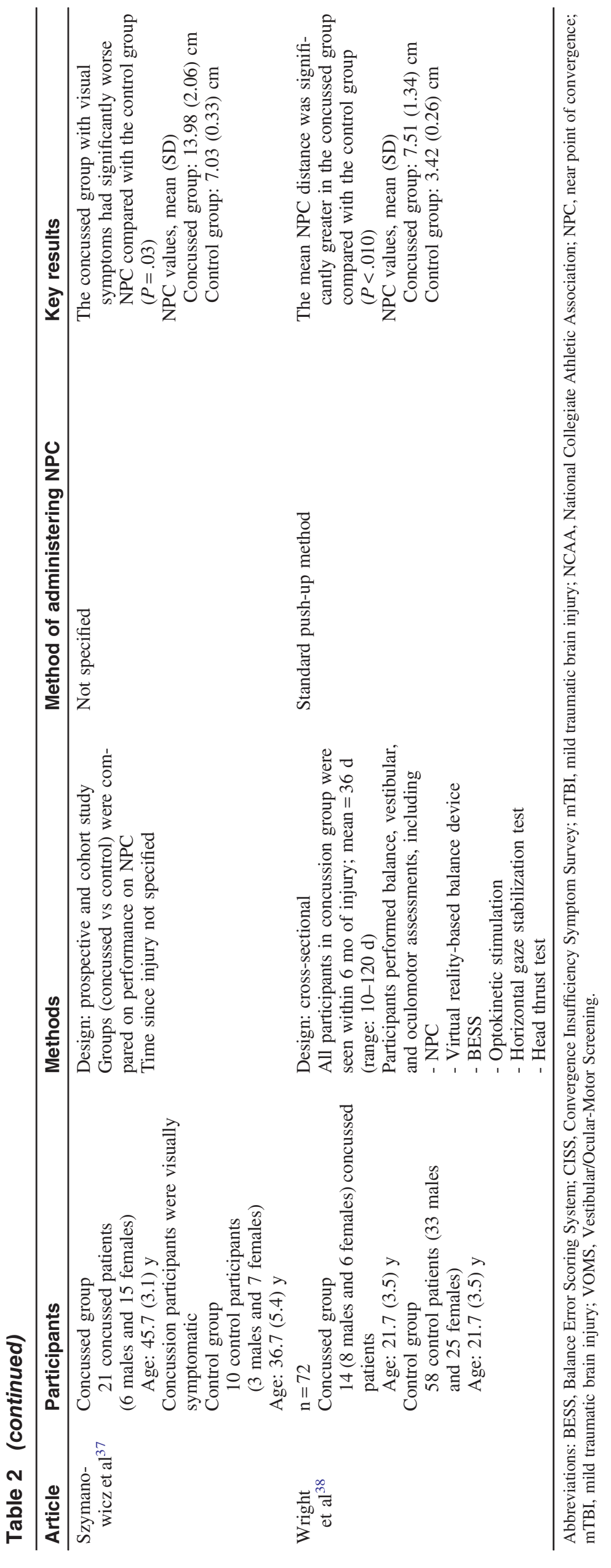


design, only a single time-point measurement of NPC was discussed. Ten studies compared individuals' performance on NPC break following concussion to healthy controls, and one study used a pretest-posttest design, where participants acted as his/her own control. The studies had various patient populations, including military personnel $(n=3), 9,31,32$ athletes $(n=4), 7,17,33,36$ and the general population $(n=4){ }^{34,35,37,38}$ The majority of the studies assessed young adults or adults $(\mathrm{n}=10)$, and one study assessed the youth population. Initial assessments were performed anywhere from 1-day postinjury to 6-month postinjury. Follow-up assessments occurred from 1-week postinjury to 10-month postinjury. Four studies did not specify how long following injury the assessments were conducted. In all 11 studies, NPC was greater (worse) in patients following concussion compared with controls or preinjury levels. Mean differences in NPC distance between concussed and healthy participants for the 9 studies that reported means and SDs are presented in Figure 2; 2 of the 11 studies did not report means or SDs. ${ }^{34,35}$ Nine of the 11 studies demonstrated a statistically significant difference in scores, with worse NPC break measurements in the concussed participants compared with controls or the participant's own baseline measures. . $^{7,9,17,31-34,37,38}$ Two studies ${ }^{35,36}$ did not demonstrate a statistically significant impairment in NPC following concussion. McDevitt et al ${ }^{36}$ demonstrated that the mean NPC distance was larger in the concussed group compared with the control group, but it was not statistically significant. Matuseviciene et $\mathrm{al}^{35}$ demonstrated a significant improvement in the mTBI group between baseline and followup, but no statistically significant difference between or within the control groups. Two studies ${ }^{34,35}$ did not report means for NPC but presented statistical results for the comparison of measures. All of the means presented for NPC during initial assessments following injury were abnormal $(>5 \mathrm{~cm})$. All of the means of the control groups were considered normal $(<5 \mathrm{~cm})$, except for in 2 of the studies, in which they were $8.18 \mathrm{~cm}^{32}$ and $7.03 \mathrm{~cm} .{ }^{37}$

Seven studies evaluated the effect of oculomotor or vision therapy on NPC break measurements in concussion/mTBI patients
(Table 3). The study designs were prospective observational trial $(\mathrm{n}=4),{ }^{24,41-43}$ retrospective cohort $(\mathrm{n}=1),{ }^{40}$ pilot study $(\mathrm{n}=1),{ }^{44}$ and case report $(\mathrm{n}=1) .{ }^{39}$ All of the studies except for Kontos et al, ${ }^{41}$ solely used vision or oculomotor therapy. Kontos et al ${ }^{41}$ prescribed targeted therapies based upon the patient's deficits, and included behavioral, vestibular, vision, and exertion therapies. The majority of the studies examined the use of oculomotor therapy in adults $(\mathrm{n}=6)$, and one study analyzed adolescents and young adults. ${ }^{24}$ Half of the studies employed therapy with a combination of in-office vision therapy and at-home reinforcement, ${ }^{24,39,40}$ whereas the remaining half used in-office therapy only. ${ }^{42-44}$ One study did not specify the type of intervention. ${ }^{41}$ Several studies did not specify the time frame that patients initiated rehabilitation, but those that did initiated therapy anywhere from 3 -week postinjury ${ }^{39}$ to 24-month postinjury. ${ }^{24}$ All of the studies demonstrated NPC break values were lower (better) after therapy. All of the studies, except for the case study, ${ }^{39}$ statistically compared participants' NPC break measurements pretherapy to posttherapy, and all 6 of them demonstrated that there was a statistically significant improvement in NPC break. Mean differences in NPC values pre-to-post vision therapy for the 3 studies that reported means and SDs are presented in Figure 3; four of the 7 studies did not report means or SDs. Even though NPC improved, the posttreatment NPC measures in studies that reported NPC measurements were still considered abnormal $(>5 \mathrm{~cm})$ in 3 of the studies ${ }^{41-43}$ and normal $(\leq 5 \mathrm{~cm})$ in 3 of the studies..$^{24,39,40}$ The lengths of the interventions were not specified in many of the studies; those that reported information had total interventions lasting from 9 hours over 6 weeks of therapy ${ }^{42}$ to 12 to 20 hours over 12 weeks of therapy. ${ }^{24}$

The QATQS resulted in 0-strong, 9-moderate, and 9weak articles (Table 4). The majority of the articles satisfied the requirements for selection bias, study design, confounders, and data collection. None of the studies were double blinded, and very few studies $(n=3)$ were single blinded. In the majority of studies, it was difficult to identify if the participants were appropriately

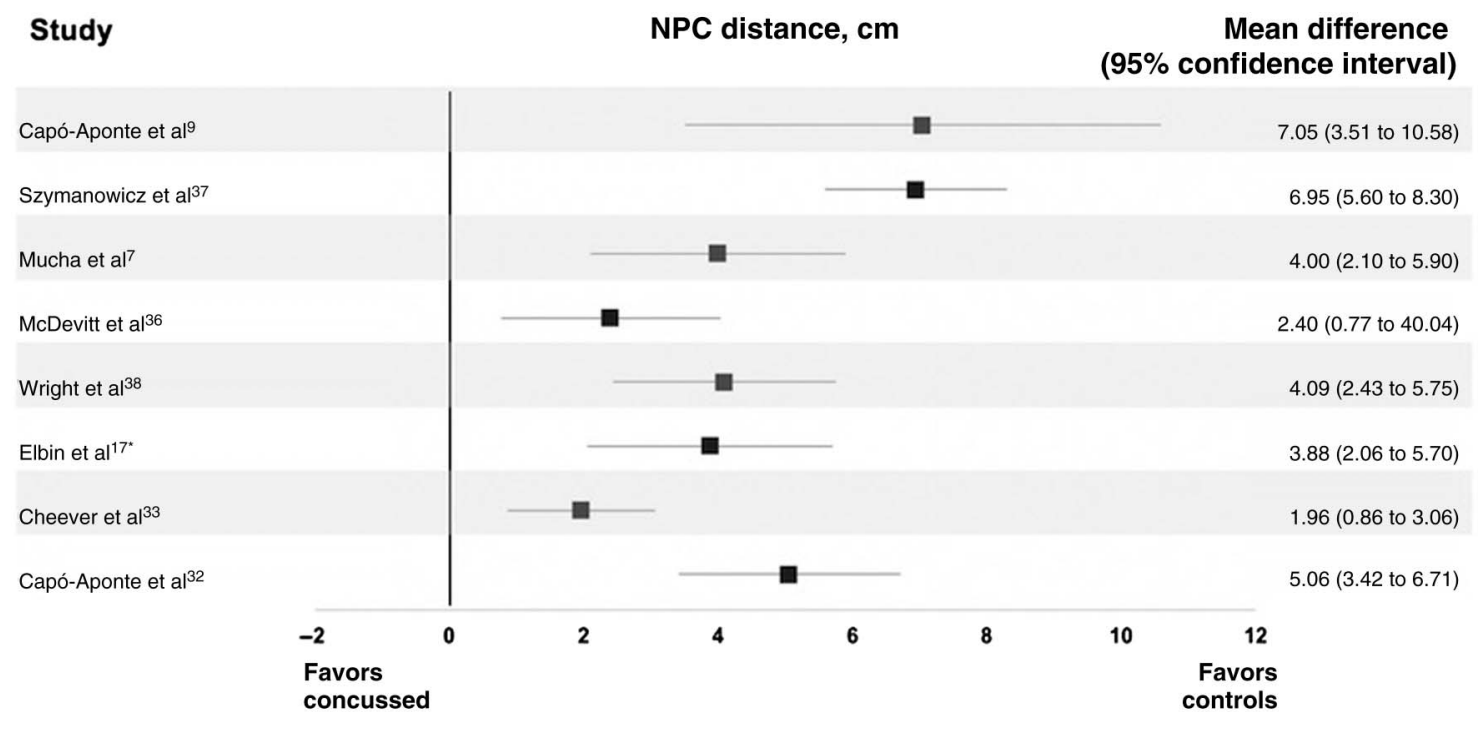

Figure 2 - Differences in near point of convergence (NPC) distance between concussed and healthy participants. Only the studies that reported means and SDs were included, as mean difference could otherwise not be calculated. The following studies did not report means or SDs: Hellerstein et al ${ }^{34}$ and Matuseviciene et al. ${ }^{35}$ There are 2 articles from Capó-Aponte et al, ${ }^{9,31}$ but both articles reported the same exact same means and SDs, so the mean difference is only listed once. For all included studies, NPC was significantly better (smaller) in the control group. *Elbin et al used preseason baselines from the same patients as the control values. 


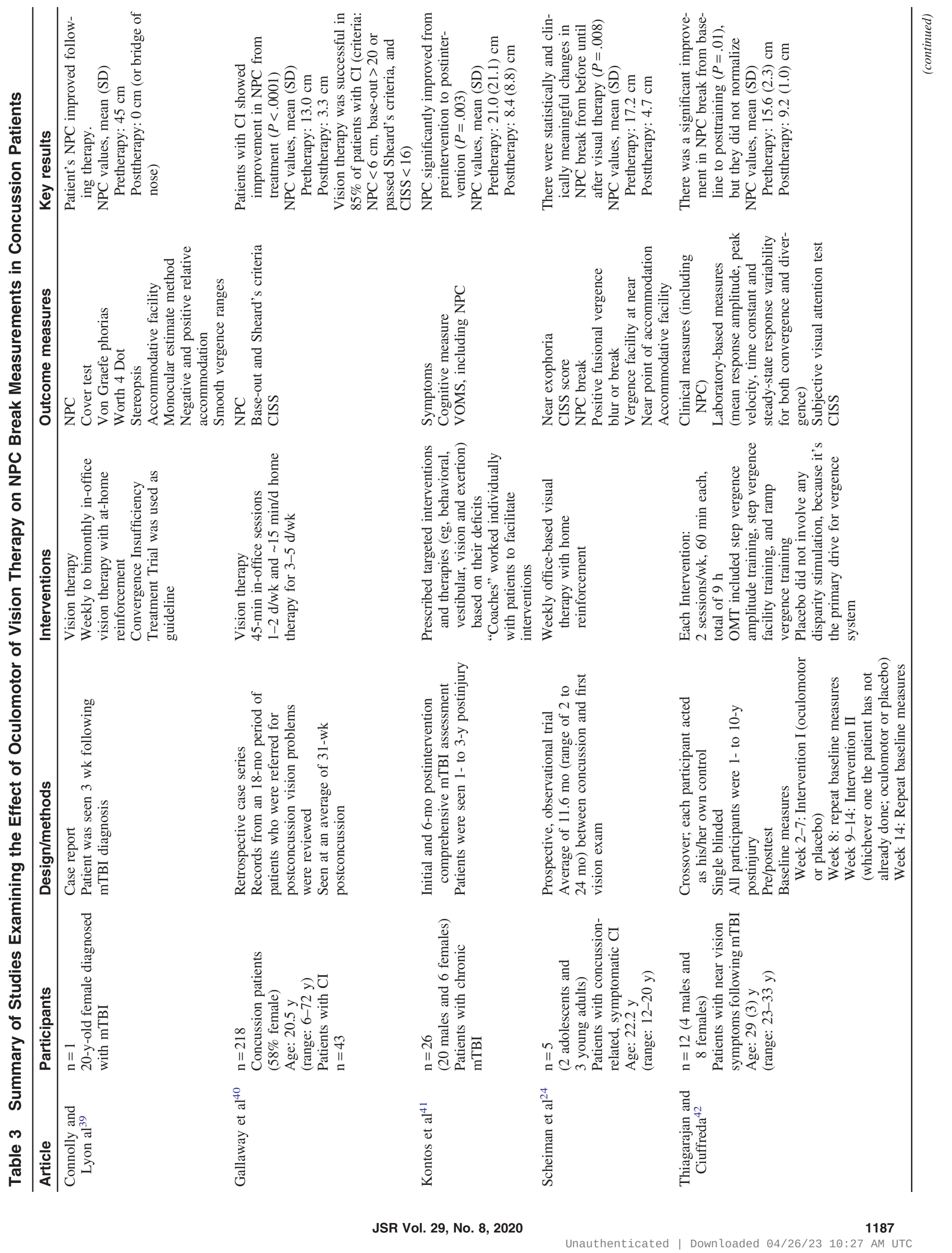




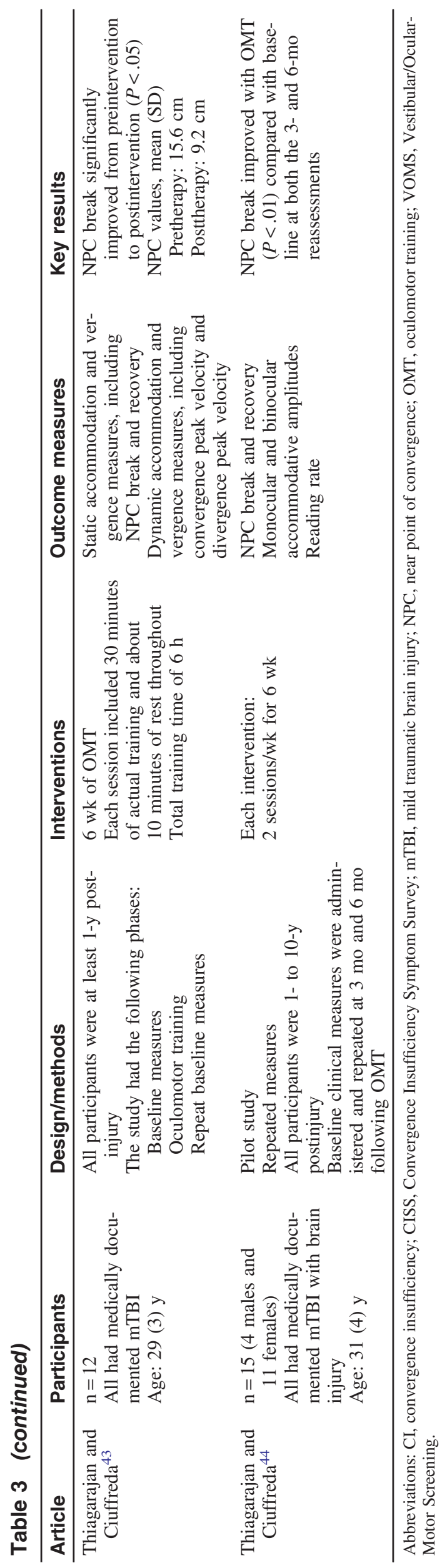




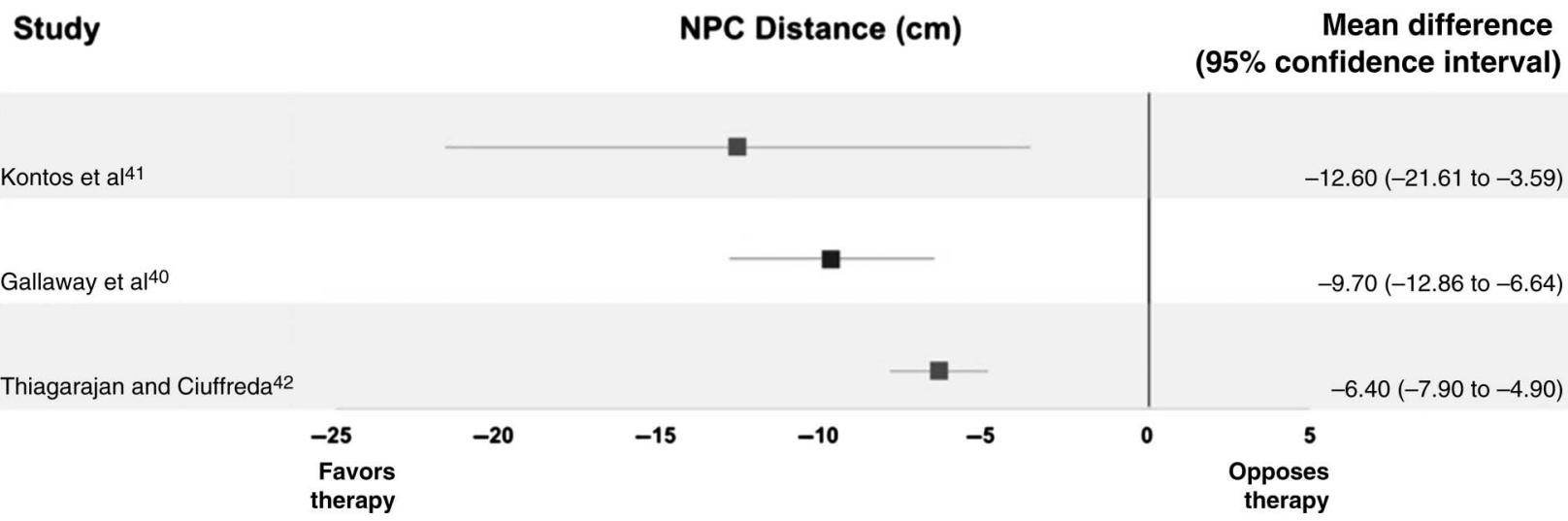

Figure 3 - Differences in near point of convergence (NPC) distance pre-to-post vision therapy. Mean differences and $95 \%$ confidence intervals for NPC distance following vision therapy. Only the studies that reported means and SDs pretreatment and posttreatment were included, as mean difference could otherwise not be calculated. The following studies did not report means or SDs: Connolly and Lyon, ${ }^{39}$ Scheiman et al, ${ }^{24}$ and Thiagarajan and Ciuffreda. ${ }^{43,44}$ For all included studies, NPC was significantly better (smaller) following vision therapy.

Table 4 Quality Appraisal of Included Studies According to the Quality Assessment Tool for Quantitative Studies

\begin{tabular}{|c|c|c|c|c|c|c|c|}
\hline Study & $\begin{array}{c}\text { Selection } \\
\text { bias }\end{array}$ & $\begin{array}{c}\text { Study } \\
\text { design }\end{array}$ & Confounders & Blinding & $\begin{array}{c}\text { Data } \\
\text { collection }\end{array}$ & Withdrawals & $\begin{array}{c}\text { Overall } \\
\text { rating }\end{array}$ \\
\hline Capó-Aponte et $\mathrm{al}^{31}$ & Moderate & Moderate & Weak & Moderate & Strong & Not applicable & Moderate \\
\hline Capó-Aponte et al ${ }^{9}$ & Moderate & Moderate & Weak & Moderate & Moderate & Not applicable & Moderate \\
\hline Capó-Aponte et $\mathrm{al}^{32}$ & Moderate & Moderate & Strong & Weak & Strong & Not applicable & Moderate \\
\hline Cheever et $\mathrm{al}^{33}$ & Moderate & Moderate & Weak & Weak & Strong & Not Applicable & Weak \\
\hline Connolly and Lyon ${ }^{39}$ & Weak & Weak & Strong & Weak & Strong & Strong & Weak \\
\hline Elbin et al ${ }^{17}$ & Moderate & Moderate & Strong & Weak & Strong & Strong & Moderate \\
\hline Gallaway et $\mathrm{al}^{40}$ & Moderate & Moderate & Strong & Weak & Moderate & Not applicable & Moderate \\
\hline Hellerstein et $\mathrm{al}^{34}$ & Moderate & Weak & Weak & Weak & Weak & Not applicable & Weak \\
\hline Kontos et $\mathrm{al}^{41}$ & Moderate & Moderate & Strong & Weak & Moderate & Weak & Weak \\
\hline Matuseviciene et $\mathrm{al}^{35}$ & Moderate & Moderate & Weak & Weak & Strong & Strong & Weak \\
\hline McDevitt et $\mathrm{al}^{36}$ & Moderate & Moderate & Moderate & Weak & Strong & Not applicable & Moderate \\
\hline Mucha et $\mathrm{al}^{7}$ & Moderate & Moderate & Moderate & Weak & Moderate & Not applicable & Moderate \\
\hline Scheiman et $\mathrm{al}^{24}$ & Weak & Moderate & Strong & Weak & Moderate & Weak & Weak \\
\hline Szymanowicz et al ${ }^{37}$ & Moderate & Moderate & Strong & Weak & Moderate & Not applicable & Moderate \\
\hline Thiagarajan and Ciuffreda ${ }^{42}$ & Weak & Moderate & Strong & Moderate & Strong & Weak & Weak \\
\hline Thiagarajan and Ciuffreda ${ }^{43}$ & Moderate & Moderate & Strong & Weak & Moderate & Weak & Weak \\
\hline Thiagarajan and Ciuffreda ${ }^{44}$ & Moderate & Moderate & Strong & Weak & Weak & Weak & Weak \\
\hline Wright et $\mathrm{al}^{38}$ & Moderate & Moderate & Strong & Weak & Moderate & Not applicable & Moderate \\
\hline
\end{tabular}

blinded. Overall, we rated the quality of evidence regarding performance on NPC break in patients diagnosed with a concussion as moderate and the evidence regarding the effect of oculomotor or vision therapy on NPC break measurements as low using GRADE.

\section{Discussion}

It is important to understand the various impairments that occur following concussion in order to create effective, evidence-based treatment paradigms. While vision assessments, such as NPC, are starting to be implemented in clinical concussion evaluations, there is little information about how these measures should be used in the evaluation and treatment of concussion. In this article, we aimed to evaluate the current literature to determine the effect of concussion on NPC and the effect of oculomotor or vision therapy on NPC break measurements in concussion patients. The key findings of this systematic review are that concussion patients have impaired NPC acutely following concussion, and oculomotor rehabilitation can improve NPC break measurements in concussion patients. The NPC values of concussed participants mentioned in this review ranged from $5.37^{33}$ to $13.98 \mathrm{~cm},{ }^{37}$ indicating that the scores were considered abnormal in all of the studies. However, Szymanowicz et al's population ${ }^{37}$ may not be representative of all concussion patients, because only patients who were experiencing visual symptoms were included in the study. In comparison, the preinjury values or control group values for NPC ranged from $1.63^{17}$ to $8.18 \mathrm{~cm}^{32}$ and were considered normal in most of the studies. These findings suggest that receded NPC is common following concussion. Therefore, including NPC as part of a multifaceted approach 
to the evaluation of concussion may lead to an increased sensitivity and specificity of the test battery. While the sensitivity and specificity of NPC as a single measure in evaluating concussion is unclear, an NPC break of $\geq 5 \mathrm{~cm}$ has a high rate $(84 \%)$ of identifying concussions and an area under the curve of $0.73 .{ }^{7}$ McDevitt et $\mathrm{al}^{36}$ recently reported that a battery including signs and symptoms scores for 2 vision tests (optokinetic stimulation and gaze stabilization tests) and NPC was a sensitive model for discriminating concussed athletes from healthy controls (accuracy $=94.4 \%$ ). Similarly, a test battery of NPC, and number of symptoms following the rapid eye horizontal, optokinetic stimulation, and gaze stabilization tests differentiated between healthy and concussed athletes with an accuracy of $90 \% .{ }^{33}$ Additionally, the Vestibular/Ocular-Motor Screening, which includes NPC, demonstrated internal consistency and sensitivity in identifying concussion patients. ${ }^{7}$ This suggests that while NPC is a very valuable concussion assessment, clinicians should continue to use a multifaceted approach that incorporates multiple systems of the body. There is moderate evidence that clinicians should implement NPC as part of a visual screening following concussion. Clinicians should consider tools that assess not only NPC, but multiple components of vision that are sensitive to concussion, including vestibular ocular reflex and visual motion sensitivity. Several screening tools and surveys are available to clinicians, such as the Vestibular/Ocular-Motor Screening, the King-Devick test (assesses saccadic eye movements), the Convergence Insufficiency Symptom Survey, and the Dizziness Handicap Inventory.

Deficits in NPC can lead to vision- and oculomotor-related symptoms, such as blurred vision, headaches, difficulty in reading, eyestrain, sleepiness, and difficulty concentrating. ${ }^{45,46}$ Visual dysfunction following concussion is also associated with decreased reading speed and comprehension. ${ }^{22}$ Athletes with CI following a sport-related concussion have worse neurocognitive impairment and higher symptoms scores than concussion patients with normal NPC. ${ }^{16}$ Specifically, athletes with CI had lower scores on measures of verbal memory, visual motor speed, and reaction time. ${ }^{16}$ The symptoms and combination of visual and cognitive deficits caused by receded NPC can result in difficulty returning to school or working, especially when completing tasks that require reading and writing. ${ }^{47}$ Clinicians should monitor NPC throughout the recovery process. Patients with impaired NPC may particularly benefit from academic or cognitive accommodations. Appropriate accommodations would include reducing the use of electronic devices, reducing brightness on screens, and considering the use of audio recordings to replace reading or note taking. ${ }^{48}$ Oculomotor dysfunction can also cause motor deficits. Adolescents with receded NPC following concussion have more gaitrelated deficits compared with healthy controls, suggesting that abnormal NPC may be related to motor system dysfunction. ${ }^{19}$ Therefore, it is imperative that NPC has returned to normal before athletes return to play. NPC break is a quick and easy measurement that can be used by clinicians to identify receded NPC. Concussion patients with receded NPC should be referred to a vision specialist for a more thorough examination to determine associated oculomotor impairments. ${ }^{20}$ While the timeline of referral is unclear, clinicians should monitor performance on NPC throughout the recovery process, and if patients are getting worse, or still have significant impairments 2 to 3 weeks following concussion, then a referral to a vision specialist should be considered. The patient population should be considered when determining the timing of referral. For example, college athletes typically recover from sport-related concussion in about 7 days, while high school athletes typically recover in 15 days. ${ }^{49}$ Therefore, referral should be considered sooner for college athletes.

Receded NPC in an otherwise healthy population is treatable through vision therapy. Randomized clinical trials have demonstrated the effectiveness of office-based vergence/accommodative therapy in the treatment of children with symptomatic CI. ${ }^{24-26}$ Currently, there are no randomized clinical trials examining the effectiveness of vision therapy in the treatment of receded NPC following concussion. It is possible that individuals diagnosed with concussion, presenting with visual or oculomotor deficits could benefit from vision or oculomotor therapy. Tailoring rehabilitation to deficits will allow clinicians to better focus interventions and treatment. Based on the 7 studies we reviewed, we assigned a GRADE rating of low level of evidence supporting the use of oculomotor or vision therapy to improve NPC break measures in patients diagnosed with concussion. All of the studies demonstrated improvements in NPC break measures following treatment. Therapy also improved symptoms, verbal memory, balance, and other visual measures. ${ }^{50}$ Most studies used a combination of office-based therapy and home reinforcement. Therapy typically included vergence-based exercises, and spectacle lenses to reduce symptoms. NPC mean improvements reported ranged from $5.4^{24}$ to $12.6 \mathrm{~cm},{ }^{50}$ while the case report demonstrated improvement of $45 \mathrm{~cm} .{ }^{39}$

Although all of the studies demonstrated an improvement in NPC values following therapy, the mean NPC values were still considered abnormal in several studies. ${ }^{24,40,51}$ Thiagarajan and Ciuffreda ${ }^{44}$ suggests that the oculomotor therapy needs to be longer in order for scores to normalize. The lengths of the interventions were not specified in many of the studies. The length of reported interventions ranged from 9 to 20 hours over 6 to 12 weeks. ${ }^{24,27}$ In individuals diagnosed with CI who are otherwise healthy, oculomotor therapy administered over 12 weeks resulted in a normalization of scores. ${ }^{52}$ This may suggest that receded NPC in concussed patients may be due to a different mechanism than in an otherwise healthy population. ${ }^{27}$ However, the improvements in NPC following oculomotor therapy were still present 6 months following therapy in concussion patients. ${ }^{44}$ The persisting effect of oculomotor therapy suggests that mechanisms of neuroplasticity and motor relearning remain intact in concussion patients. ${ }^{44}$ There are a variety of treatments available for addressing impaired NPC, including both office- and home-based programs. Office-based treatments are typically administered by a vision therapist (O.D., M.D., orthoptists, or vision therapy-trained technicians) and often includes the use of Brock Strings, Barrel Cards, Vectograms, and Life-Saver cards. ${ }^{26}$ Home-based therapy is often prescribed by optometrists and ophthalmologists, and it provides a cost-effect option. ${ }^{53}$ Home-based therapies typically include simple exercises, such as pencil push-ups and computer-based software. Several software programs and web-based applications have been developed for vision therapy, such as CVS, Computerized Home Vision Therapy Systems, Vision Therapy Solutions, and Oculomotor Therapy Program. The treatment of CI is beneficial, with $85 \%$ of patients having a successful outcome. ${ }^{40}$ Treatment of accommodative insufficiency was only successful in $33 \%$ of patients, and treatment of saccadic dysfunction was successful in $83 \%$ of patients. ${ }^{40}$ Therefore, concurrent or underlying oculomotor dysfunctions associated with receded NPC may play a role in how a patient responds to therapy. It is important to determine if specific oculomotor deficits (eg, CI or an accommodative disorder) or individual characteristics (eg, age, sex, and medical history) influence whether or not those with receded NPC recover spontaneously or require therapy, and whether or not they respond to therapy. 
While the results of this systematic review are promising, showing that impaired NPC following concussion can be improved through oculomotor therapy, more research in this area is needed. NPC values reported in the literature and in this systematic review vary greatly. Differences in mean NPC values could be due to differences in ages of the patient populations or the type of target or assessment used to measure NPC, which was not specified in several studies. In order to aid in interpretation and clinical implications of findings, future studies should specify the target type and methods used for the assessment of NPC. Additionally, there is little information about normative values on NPC for athletes. Given that concussions are common in sports, future studies should determine if current cutoff scores for abnormal NPC in the general population are applicable to athletes. Additionally, the effect of age on NPC measures should be further established. It is possible that a baseline postinjury comparison would be more accurate than clinical cutoffs at diagnosing deficits in athletes. Several of the studies included in this systematic review examined non-sport-related mechanisms of injury (eg, jumping from an airplane, blast exposure, motor vehicle accidents or assault) and severities of injury that may not be generalizable to sport-related concussion. ${ }^{32}$ Additionally, data were collected at fairly large time intervals following concussion, so more information about recovery trajectories for NPC following concussion is necessary. Furthermore, several of the studies included in this review seem to report redundant data with the same or very similar findings in both studies by the same first author. ${ }^{9,31,43,51}$ Finally, studies often failed to control for factors that may affect NPC, such as age; sex; and history of visual, oculomotor, or vestibular abnormalities. Future studies should determine factors that affect whether or not individuals experience abnormal NPC following concussion. It is suggested that a history of ocular motor dysfunction, such as nystagmus or strabismus may be risk factors for poor outcomes following concussion. ${ }^{5}$ Therefore, future studies should take these potential confounding variables into account when evaluating NPC postconcussion.

Randomized, controlled studies determining whether or not performing vision therapy improves NPC and other visual measures (such as accommodation, saccades, etc) in order to aid in recovery following concussion are needed. Additionally, future studies should focus on the best timeline for implementing visual rehabilitation. In the current studies, 3-week postinjury ${ }^{39}$ is the earliest oculomotor rehabilitation was initiated, while several studies waited at least 1 year following injury to initiate rehabilitation. ${ }^{41-44}$ With timelines for implementing therapy being so widespread, it is unclear what timeframe is most beneficial for treatment of CI following concussion. It is possible that initiating oculomotor therapy earlier in the rehabilitation process may result in improved recovery. Future studies should focus on identifying the best timeline for implementing oculomotor rehabilitation in post-concussion patients with visual dysfunction.

This systematic review is not without its limitations. Due to the mix of observational and interventional studies and the lack of clinical trials, an in-depth analysis of methodological quality and risk of bias was not included. In addition, because of the small number of studies that included a repeated-measures evaluation of NPC in concussion patients, and the heterogeneity of the patient populations and study designs, a meta-analysis was not performed. While we were able to include 18 articles in this review, the majority of articles did not meet requirements for blinding. The relevance of blinding varies according to the circumstances and is less important for studies using objective outcomes. ${ }^{54}$ If the blinding component of the QATQS was not considered when determining the overall rating, then 7 of the studies would have been categorized as strong, 6 as moderate, and 5 as weak. However, using the overall rating according to the QATQS, the articles were considered moderate $(n=9)$ and weak $(n=9)$. Additionally, one of the articles is a case report, and is therefore a low level of evidence and is not sufficient to generate clinical recommendations. The overall rating of evidence for the clinical recommendations presented in this paper based on GRADE is low to moderate. Therefore, the findings from studies with lower levels of evidence need to be cautiously evaluated, before they are implemented into clinical practice. This highlights the need for higher level studies, such as randomized control trials, evaluating the effects of concussion on NPC and the efficacy of oculomotor and vision therapy in the treatment of CI following concussion.

\section{Conclusions}

This review evaluated the available literature on the effect of concussion on NPC break measures and the effect of oculomotor or vision therapy on NPC break measurements. The results suggest that individuals have impaired NPC following concussion, and that vision therapy improves NPC in concussion patients. While the results of the review are promising, there is a lot of heterogeneity in the patient populations and methodology in the studies included in this review. Given the available evidence, we conclude that NPC should be included as an assessment following concussion in order to determine the patients who need referral for further evaluation and may benefit from vision or oculomotor therapy to promote recovery. Future research should continue to explore factors affecting convergence following concussion and include randomized, controlled studies to determine whether or not performing vision therapy improves visual measures to promote recovery following concussion.

\section{References}

1. McCrory P, Feddermann-Demont N, Dvoøák J, et al. What is the definition of sports-related concussion: a systematic review. $\mathrm{Br} \mathrm{J}$ Sports Med. 2017;51(11):877-887. PubMed ID: 29098981 doi:10. 1136/bjsports-2016-097393

2. Sterr A, Herron KA, Hayward C, Montaldi D. Are mild head injuries as mild as we think? Neurobehavioral concomitants of chronic post-concussion syndrome. BMC Neurol. 2006;6:7. PubMed ID: 16460567 doi:10.1186/1471-2377-6-7

3. McCrory P, Meeuwisse W, Dvořák J, et al. Consensus statement on concussion in sport - the 5th international conference on concussion in sport held in Berlin, October 2016. Br J Sports Med. 2017; 51(11):838-847. PubMed ID: 28446457 doi:10.1136/bjsports-2017097699

4. Ellis MJ, Leddy JJ, Willer B. Physiological, vestibulo-ocular and cervicogenic post-concussion disorders: an evidence-based classification system with directions for treatment. Brain Inj. 2015;29(2):238248. PubMed ID: 25314613 doi:10.3109/02699052.2014.965207

5. Collins MW, Kontos AP, Reynolds E, Murawski CD, Fu FH. A comprehensive, targeted approach to the clinical care of athletes following sport-related concussion. Knee Surg Sports Traumatol Arthrosc. 2014;22(2):235-246. PubMed ID: 24337463 doi:10. 1007/s00167-013-2791-6

6. Craton N, Ali H, Lenoski S. COACH CV: the seven clinical phenotypes of concussion. Brain Sci. 2017;7(9):119. PubMed ID: PMC5615260 doi:10.3390/brainsci7090119 
7. Mucha A, Collins MW, Elbin RJ, et al. A brief Vestibular/Ocular Motor Screening (VOMS) assessment to evaluate concussions: preliminary findings. Am J Sports Med. 2014;42(10):2479-2486. PubMed ID: 25106780 doi:10.1177/0363546514543775

8. Sells SB, Fixott RS. Evaluation of research on effects of visual training on visual functions. Am J Ophthalmol. 1957;44(2):230-236. PubMed ID: 13444415 doi:10.1016/0002-9394(57)90012-0

9. Capó-Aponte JE, Urosevich TG, Temme LA, Tarbett AK, Sanghera NK. Visual dysfunctions and symptoms during the subacute stage of blast-induced mild traumatic brain injury. Mil Med. 2012;177(7): 804-813. doi:10.7205/MILMED-D-12-00061

10. Goodrich GL. Visual function in patients of a polytrauma rehabilitation center: a descriptive study. J Rehabil Res Dev. 2009;44(7):929936. doi:10.1682/JRRD.0000.00.0000

11. Ciuffreda KJ, Kapoor N, Rutner D, Suchoff IB, Han ME, Craig S. Occurrence of oculomotor dysfunctions in acquired brain injury: a retrospective analysis. Optometry. 2007;78(4):155-161. PubMed ID: 17400136 doi:10.1016/j.optm.2006.11.011

12. Master CL, Scheiman M, Gallaway M, et al. Vision diagnoses are common after concussion in adolescents. Clin Pediatr. 2016;55(3): 260-267. PubMed ID: 26156977 doi:10.1177/0009922815594367

13. Ventura RE, Balcer LJ, Galetta SL. The concussion toolbox: the role of vision in the assessment of concussion. Semin Neurol. 2015;35(5): 599-606. PubMed ID: 26444405 doi:10.1055/s-00000071

14. Scheiman M, Gallaway M, Frantz KA, et al. Nearpoint of convergence: test procedure, target selection, and normative data. Optom Vis Sci. 2003;80(3):214-225. PubMed ID: 12637833 doi:10.1097/ 00006324-200303000-00011

15. Adler PM, Cregg M, Viollier AJ, Margaret Woodhouse J. Influence of target type and RAF rule on the measurement of near point of convergence. Ophthalmic Physiol Opt. 2007;27(1):22-30. PubMed ID: 17239187 doi:10.1111/opo.2007.27.issue-1

16. Pearce KL, Sufrinko A, Lau BC, Henry L, Collins MW, Kontos AP. Near point of convergence after a sport-related concussion. Am J Sports Med. 2015;43(12):3055-3061. PubMed ID: 26453625 doi:10. $1177 / 0363546515606430$

17. Elbin RJ, Sufrinko A, Anderson MN, et al. Prospective changes in vestibular and ocular motor impairment after concussion. J Neurol Phys Ther. 2018;42(3):142-148. PubMed ID: 29864101 doi:10. 1097/NPT.0000000000000230

18. Carlson NB, Kurtz D, Heath DA. Clinical Procedures for Ocular Examination. Norwalk, CT: Appleton \& Lange; 1990.

19. Howell DR, O'Brien MJ, Raghuram A, Shah AS, Meehan WP. Near point of convergence and gait deficits in adolescents after sportrelated concussion. Clin J Sport Med. 2018;28(3):262-267. PubMed ID: 28742610 doi:10.1097/JSM.0000000000000439

20. Raghuram A, Cotter S, Gowrisankaran S, et al. Post-concussion: receded near point of convergence is not diagnostic of convergence insufficiency. Am J Ophthalmol. 2019;206:235-244. PubMed ID: 31004592 doi:10.1016/j.ajo.2019.04.008

21. Duprey KM, Webner D, Lyons A, Kucuk CH, Ellis JT, Cronholm PF. Convergence insufficiency identifies athletes at risk of prolonged recovery from sport-related concussion. Am J Sports Med. 2017;45(10): 2388-2393. PubMed ID: 28511593 doi:10.1177/0363546517705640

22. Thiagarajan P, Ciuffreda KJ, Capó-Aponte JE, Ludlam DP, Kapoor N. Oculomotor neurorehabilitation for reading in mild traumatic brain injury (mTBI): an integrative approach. NeuroRehabilitation. 2014; 34(1):129-146. PubMed ID: 24284470 doi:10.3233/NRE-131025

23. Christenson G, Winkelstein A. Visual skills of athletes versus nonathletes: development of a sports vision testing battery. J Am Optom Assoc. 1988;59(9):666-675. PubMed ID: 3183281

24. Scheiman MM, Talasan H, Lynn Mitchell G, Alvarez TL. Objective assessment of vergence after treatment of concussion-related CI: a pilot study. Optom Vis Sci. 2017;94(1):74-88. PubMed ID: 27464574 doi:10.1097/OPX.0000000000000936

25. Scheiman M, Cotter S, Mitchell GL, et al. Randomized clinical trial of treatments for symptomatic convergence insufficiency in children. Arch Ophthalmol. 2008;126(10):1336-1349. doi:10.1001/archopht. 126.10.1336

26. Scheiman M, Mitchell GL, Cotter S, et al. The convergence insufficiency treatment trial: design, methods, and baseline data. Ophthalmic Epidemiol. 2008;15(1):24-36. doi:10.1080/09286580701772037

27. Thiagarajan P, Ciuffreda KJ. Effect of oculomotor rehabilitation on accommodative responsivity in mild traumatic brain injury. $J$ Rehabil Res Dev. 2014;51(2):175-191. PubMed ID: 24933717 doi:10.1682/ JRRD.2013.01.0027

28. Thomas H, Ciliska D, Dobbins M. Quality Assessment Tool for Quantitative Studies. Toronto, ON: Effective Public Health Practice Project; 2003.

29. Armijo-Olivo S, Stiles CR, Hagen NA, Biondo PD, Cummings GG. Assessment of study quality for systematic reviews: a comparison of the cochrane collaboration risk of bias tool and the effective public health practice project quality assessment tool: methodological research. $J$ Eval Clin Pract. 2012;18(1):12-18. PubMed ID: 20698919 doi: 10. 1111/jep.2012.18.issue-1

30. Siemieniuk R, Guyatt G. What is GRADE? BMJ Best Pract. 2019. https://bestpractice.bmj.com/info/us/toolkit/learn-ebm/what-is-grade/. Accessed February 20, 2020.

31. Capó-Aponte JE, Tarbett AK, Urosevich TG, Temme LA, Sanghera NK, Kalich ME. Effectiveness of computerized oculomotor vision screening in a military population: pilot study. J Rehabil Res Dev. 2012;49(9):1377-1398. doi:10.1682/JRRD.2011.07.0128

32. Capó-Aponte JE, Beltran TA, Walsh DV, Cole WR, Dumayas JY. Validation of visual objective biomarkers for acute concussion. Mil Med. 2018;183(suppl 1):9-17. doi:10.1093/milmed/usx166

33. Cheever KM, McDevitt J, Tierney R, Wright WG. Concussion recovery phase affects vestibular and oculomotor symptom provocation. Int J Sports Med. 2018;39(2):141-147. PubMed ID: 29190849 doi:10.1055/s-0043-118339

34. Hellerstein LF, Freed S, Maples WC. Vision profile of patients with mild brain injury. J Am Optom Assoc. 1995;66(10):634-639. PubMed ID: 7499718

35. Matuseviciene G, Johansson J, Möller M, Godbolt AK, Pansell T, Deboussard CN. Longitudinal changes in oculomotor function in young adults with mild traumatic brain injury in Sweden: an exploratory prospective observational study. BMJ Open. 2018;8:e018734. doi:10.1136/bmjopen-2017-018734

36. McDevitt J, Appiah-Kubi KO, Tierney R, Wright WG. Vestibular and oculomotor assessments may increase accuracy of subacute concussion assessment. Int J Sports Med. 2016;37(9):738-747. PubMed ID: 27176886 doi:10.1055/s-0042-100470

37. Szymanowicz D, Ciuffreda KJ, Thiagarajan P, Ludlam DP, Green W, Kapoor N. Vergence in mild traumatic brain injury: a pilot study. J Rehabil Res Dev. 2012;49(7):1083-1100. PubMed ID: 23341281 doi:10.1682/JRRD.2010.07.0129

38. Wright WG, Tierney RT, McDevitt J. Visual-vestibular processing deficits in mild traumatic brain injury. $J$ Vestib Res Equilib Orientat. 2017;27(1):27-37. PubMed ID: 28387693 doi:10.3233/VES170607

39. Connolly K, Lyon DW. In-office vision therapy for the treatment of post-concussion syndrome: is it beneficial? A case report. J Optom Vis Perform. 2017;5(6):221-223.

40. Gallaway M, Scheiman M, Lynn Mitchell G. Vision therapy for postconcussion vision disorders. Optom Vis Sci. 2017;94(1):68-73. PubMed ID: 27505624 doi:10.1097/OPX.0000000000000935 
41. Kontos AP, Collins MW, Holland CL, et al. Preliminary evidence for improvement in symptoms, cognitive, vestibular, and oculomotor outcomes following targeted intervention with chronic mTBI patients. Mil Med. 2018;183(suppl 1):333-338. PubMed ID: 29635578 doi:10.1093/milmed/usx 172

42. Thiagarajan P, Ciuffreda KJ. Effect of oculomotor rehabilitation on vergence responsivity in mild traumatic brain injury. $J$ Rehabil Res Dev. 2013;50(9):1223-1240. PubMed ID: 24458963 doi:10.1682/ JRRD.2012.12.0235

43. Thiagarajan P, Ciuffreda KJ. Accommodative and vergence dysfunctions in mTBI: treatment effects and systems correlations. Optom Vis Perform. 2014;2(6):280-288.

44. Thiagarajan P, Ciuffreda KJ. Short-term persistence of oculomotor rehabilitative changes in mild traumatic brain injury (mTBI): a pilot study of clinical effects. Brain Inj. 2015;29(12):1475-1479. PubMed ID: 26308101 doi:10.3109/02699052.2015.1070905

45. Borsting EJ, Rouse MW, Mitchell GL, et al. Validity and reliability of the revised convergence insufficiency symptom survey in children aged 9 to 18 years. Optom Vis Sci. 2003;80(12):832838. PubMed ID: 14688547 doi:10.1097/00006324-20031200000014

46. Borsting E, Rouse MW, Deland PN, et al. Association of symptoms and convergence and accommodative insufficiency in school-age children. Optometry. 2003;74(1):25-34. PubMed ID: 12539890

47. Storey EP, Master SR, Lockyer JE, Podolak OE, Grady MF, Master CL. Near point of convergence after concussion in children. Optom Vis Sci. 2017;94(1):96-100. PubMed ID: 27391530 doi:10.1097/ OPX.0000000000000910
48. Halstead ME, Mcavoy K, Devore CD, Carl R, Lee M, Logan K. Returning to learning following a concussion. Pediatrics. 2013; 132(5):948-957. PubMed ID: 24163302 doi:10.1542/peds.2013-2867

49. Williams RM, Puetz TW, Giza CC, Broglio SP. Concussion recovery time among high school and collegiate athletes: a systematic review and meta-analysis. Sport Med. 2015;45(6):893-903. PubMed ID: 25820456 doi:10.1007/s40279-015-0325-8

50. Kontos AP, Sufrinko A, Elbin RJ, Puskar A, Collins MW. Reliability and associated risk factors for performance on the Vestibular/ Ocular Motor Screening (VOMS) tool in healthy collegiate athletes. Am J Sports Med. 2016;44(6):1400-1406. PubMed ID: 26980845 doi:10.1177/0363546516632754

51. Thiagarajan P, Ciuffreda KJ. Versional eye tracking in mild Traumatic Brain Injury (mTBI): effects of Oculomotor Training (OMT). Brain Inj. 2014;28(7):930-943. PubMed ID: 24826956 doi:10.3109/ 02699052.2014 .888761

52. Scheiman M, Mitchell GL, Cotter S, et al. A randomized clinical trial of treatments for convergence insufficiency in children. Arch Ophthalmol. 2005;123(1):14-24. PubMed ID: 15642806 doi:10. 1001/archopht.123.1.14

53. Momeni-Moghaddam H, Kundart J, Azimi A, Hassanyani F. The effectiveness of home-based pencil push-up therapy versus officebased therapy for the treatment of symptomatic convergence insufficiency in young adults. Middle East Afr J Ophthalmol. 2015; 22(1):97-102. PubMed ID: 25624682 doi:10.4103/0974-9233. 148357

54. Day S, Altman D. Blinding in clinical trials and other studies. Br Med J. 2000;321:504-504. doi:10.1136/bmj.321.7259.504 